\title{
New Records of Mealybugs on Sprouted Potatoes in Storage at Kulumsa, South East Ethiopia - A Potential Future Threat for Potato Production
}

\author{
Fekadu Gebretensay Mengistu* Gizaw Wogayehu Tilahun \\ Ethiopian Institute of Agricultural Research (EIAR), Kulumsa Agricultural Research Center (KARC), P.O.Box \\ 489, Asella, Ethiopia
}

\begin{abstract}
Potato has lived with several diseases and insect pests such as late blight and potato tuber moth for several decades. However, newly emerging insect pest known by the name 'mealybug' is recorded as a new threat for potato production in the highlands of Arsi, Southeast Ethiopia. This pest has never been observed in the area in the history of potato culture in which potato has been grown for many years. Therefore, awareness creation should be the primary step by which any respective stakeholders including potato growers, research institutions, ministry of agriculture; NGOS, etc. are informed about the importance of the pest. This will help to look for appropriate management options and take the necessary precautions before the pest becomes important in other areas in the country.
\end{abstract}

Keywords: DLS, Potato tubers, Solanum tuberosum, Storage pest

DOI: $10.7176 / \mathrm{JBAH} / 10-11-03$

Publication date:June $30^{\text {th }} 2020$

\section{Introduction}

Potato is dominantly produced in all Arsi highland areas particularly in Tiyo district - Kulumsa PA from crop land of $43.6 \%$ (FAO, 2008). In addition to the 'Belg' season, farmers in the area produce potatoes in the rainy season because of the increasing demand of the crop, and to maximize the productivity of the land per unit area due to the subsequent decrease of the average farm land size. The potato varieties grown in the area are low yielding due to susceptibility to late blight disease. Hence, the productivity of the crop under farmer's management ranges from 8 to $15 \mathrm{t} \mathrm{ha}^{-1}$ (Arsi Zone ARDO, 2007) which is very low as compared to that of the research management $\left(>20 \mathrm{t} \mathrm{ha}^{-}\right.$ ${ }^{1}$ ). The leading problems associated with the very low yield are lack of improved varieties and use of inferior quality seed tubers of unknown origin, high disease incidence (mainly late blight), insect damage such as Potato Tuber Moth (PTM), lack of proper crop management practices, inappropriate storage structure, poor seed system and poor research-extension linkage (Gebremedhin et al., 2008). Moreover, lack of storage facilities for seed and ware potatoes and traditional storage system used by many farmers contribute to sever losses of potatoes in storage. About $30-50 \%$ of the annual potato production is lost after harvest because of poor farm- and village-level storage system (Buys and Nortje,1997).

The prevalence of those production constraints mentioned above have contributed to the low productivity of the crop in Arsi highlands including Kulumsa until the introduction of improved production technologies such as improved varieties and production technologies through the research system. However, seed constitutes a very important part of potato cultivation as it accounts for higher percent of the total cost and it is the main source of diseases and insect pests. Unavailability of good quality and healthy seed potatoes at the right time becomes the major problem in potato cultivation. By using diffused light stores (DLS), farmers are able to store their own seed stocks, instead of buying seeds of unknown health state from distant suppliers. However, this is not always true for many potato growers. Most farmers are compelled to buy seeds from other areas whenever there is seed shortage. For many years however, potato tuber moth (Phthorimae operculella) has been the major insect pest of stored potatoes which causes significant damage on tubers in storages. However, currently the new invasive insect pest called Mealybug emerges as a serious problem to stored potato seeds at Kulumsa Agricultural Research Center (KARC). This pest has never been reported before at KARC and elsewhere in the country as a potential pest on potatoes. The pest was primarily identified as Mealybug based on its morphological appearance, the nature of damage \& symptoms it causes on the tubers. It was first observed in 2015 and then in 2016 and 2017 on sprouted potatoes in a DLS at KARC (Authors' observation). However during these periods, the pest was not recognized as potential threat since the infestation was not severe and there was no significant damage and researchers barely know about the pest. Nevertheless, later in 2018 and this year (2019) it emerged as serious insect pest infesting potato tubers stored for sprouting in DLS and it became high enough to be reported as an outbreak. Hence, the occurrence of this strange pest in the area created high concern among potato research teams. This short report is therefore intended to create awareness about the importance of the pest among potato growers and any respective stakeholders including research institutions, higher institutions, District Bureau of agriculture and NGOs. It could also be used as an alarm to give due attention, understand the pest and look for appropriate management options 
before the pest becomes a potential threat for potato production.

\section{What did we observe in the potato store (DLS)?}

The pest was not appearing on fresh tubers when it brought in to the store after harvest. However, it came into view later 4-5 month of storage when tubers were sprouting. The level of the infestation has increased with time as the pest multiplied rapidly feeding on the sap from sprouts. The insect had white mass of cottony like cocoon which appeared in different developmental stages (instars) having different body sizes (Figure 1A). Adult Mealybug bodies are distinctly segmented and usually covered with wax. Older individuals may have wax filaments around their body margins. In some species the filaments are longer in the rear and can be used to help distinguish between different species. The pest forms white mass of thread like web on the surface of the sprouts, which is probably the protective case where the females lay their eggs inside (Figure 1B). It is more likely to see high population of the pest on the sprouted tubers placed in piled thick layers as the pest likes to feed in colonies usually between tuber touches in protected areas. Besides, it was not uncommon to see honey dew like fluid on the surface of the tubers where the infestation was severe (Figure 1D). In a bad infestation, their waxy excretions (also known as honeydew) encourages the development of sooty mold fungus which later causes tubers rotting. (Figure 1C).
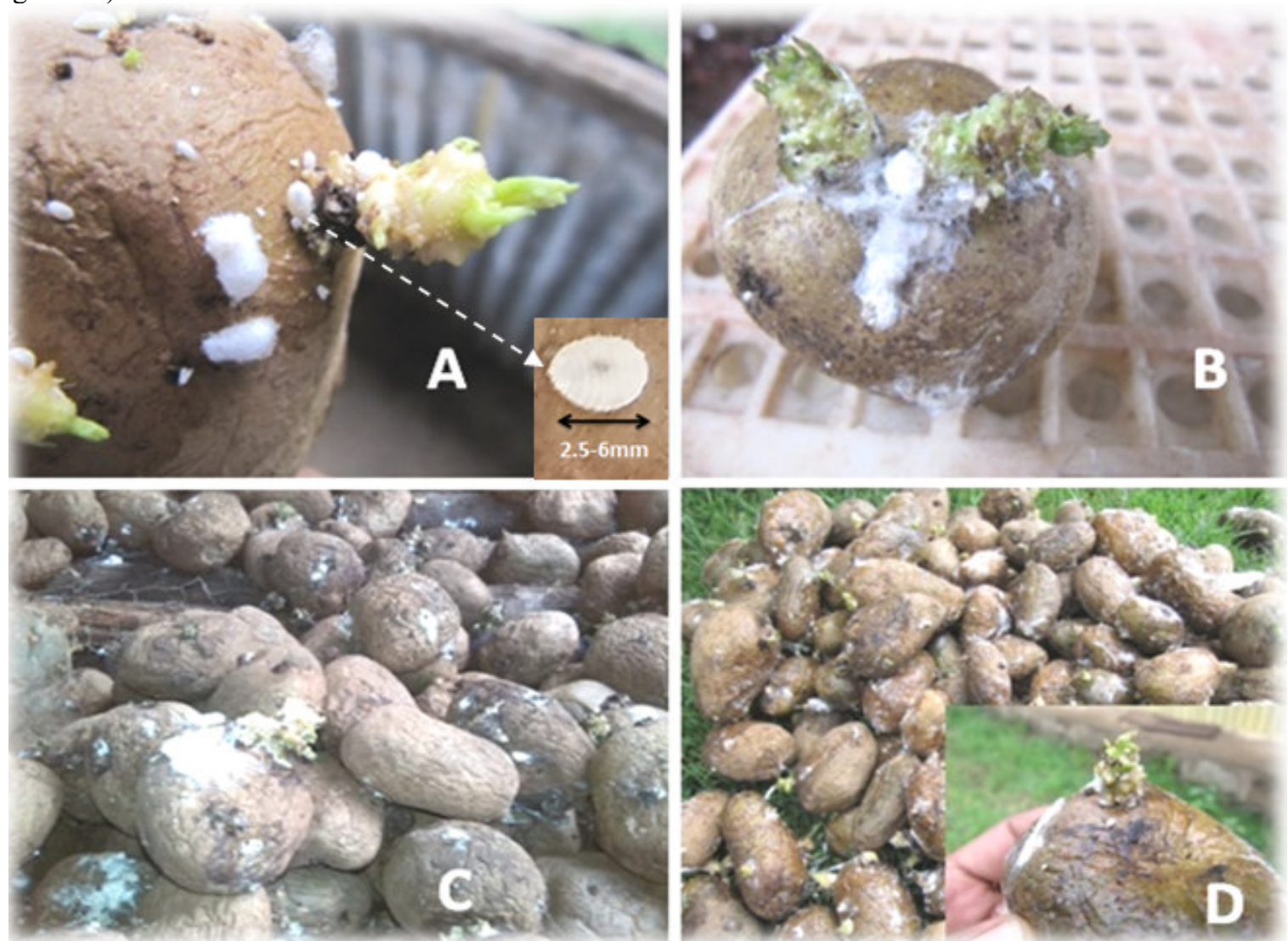

Figure 1. Pictures taken in DLS stores at different stages of the infestation. A-when adult Mealybugs feeding on the sprouts; B- Mealybugs formed white thread like webs on the sprouts; C-Sooty mold fungus on severely infested tubers and D-waxy honeydew excretions on the surface of infested tubers.

From our observation, we could speculate that the pest can overwinter in the store hiding under barks and between touches of wooden materials used to construct the store and also on the underside of plastic boxes used to temporarily store and transport tubers (Figure 2). Hence, there is high chance for the pest to make re-infestations in the stores whenever stored potatoes are sprouting and the environment is favorable.

\subsection{Possible sources of the pest}

It is still unclear whether the sources of the pest could either be from the field or the store itself. There should be some possible sources which we may probably suggest from our observation. Since the pest is less mobile and does not move long distance, the more likely source could be from seed tubers which are usually come from other places since there is always movement of seed tubes between research centers to exchange planting materials (sprouted tubers) for research purposes. Hence, it could be a suitable means by which the pest could move easily from one place to another and cause such kind of infestation in areas where the pest has never been before. 


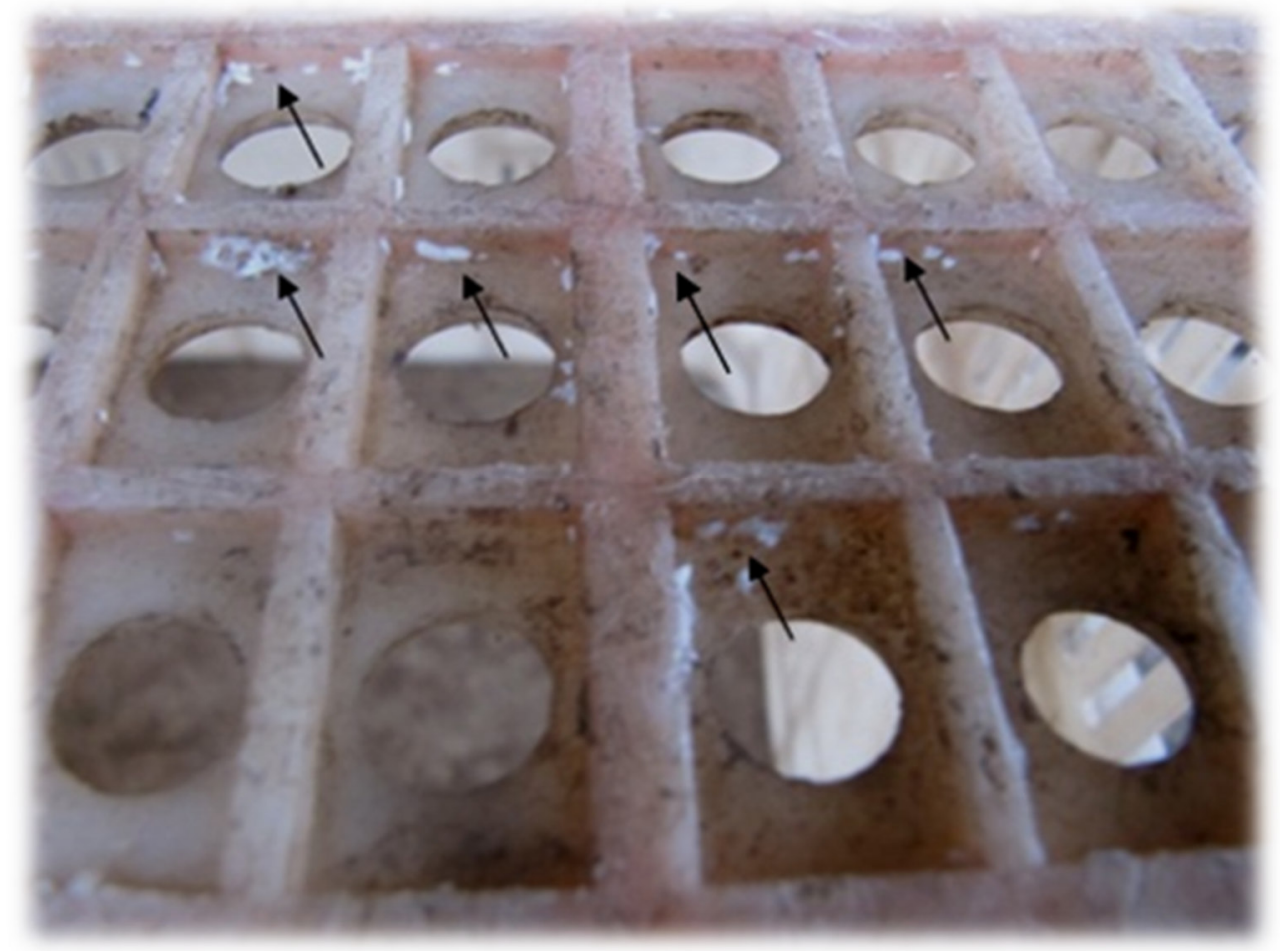

Figure 2. The underside of a plastic box, used to temporarily store and transport potato tubers from field to stores and vice versa. The pest uses to hide on the edges of the boxes until the next infestation. The arrows indicate the young of the pest hiding on the underside of the box.

The other likely source could be different plant harvests other than potato tubers which might bring the pest into the store. Since Mealybugs have a wide host range, it may come to the potato store with samples of different plant harvests, such as pumpkins, garlic, onions, shallots, seed spices, etc., which are temporarily kept in the stores.

It has been recorded from 154 plant species including field crops, vegetables, ornamentals, weeds, bushes and trees (Arif et al., 2009; Saini et al.,2009). Most of these belong to the family Malvaceae, Solanaceae, Asteraceae, Euphorbiaceae, Amaranthaceae and Cucurbitaceae, however, the economical damage has been observed on cotton, okra, tomato, sesame, sunflower and China rose (Arif et al., 2009).The oleander Mealybug, Paracoccus burnerae (Brain), occurs from Kenya to South Africa and attacks approximately 35 species of plants, including important food and beverage crops such as potatoes, olives and coffee (www.sel.barc.usda.gov/scalenet/scalenet.htm) (Johnson and Giliomee, 2011). Butternut, pumpkins and sprouting potatoes have been found to be suitable substrates for the mass rearing of various Coccoidea (Blumberg and Swirski, 1977; Elder and Smith, 1995), the super family to which Mealybugs belong. The Mealybug is a significant pest of many tropical and subtropical fruits, vegetables, and ornamental plants (Miller and Miller, 2002), and it has a wide host range, including Carica papaya L. (papaya), Persea americana P. Mill. (avocado), Citrus spp. (citrus), Solanum melongena L. (eggplant), Hibiscus spp. (hibiscus), Plumeria spp. (plumeria), and Acalypha spp. (acalypha) (Walker et al., 2006).

\subsection{What measures were taken?}

Since the infestation was accidental and occurred with no control options at hand, the first measure was to consult entomologist and take whatever possible options available so as to contain the pest in the store and prevent it from spreading to other areas. Hand picking and sanitation were the first measures undertaken to minimize the scale of the infestation and prevent it from spreading within the stores itself. Since there were no any research recommended insecticides at hand at the time of the outbreak, the only option other than hand picking and sanitation was to spray systemic insecticides such as Karate and Profit with a perception that Mealybugs are sap feeding insects. In addition, contact insecticide (Endosulfan) was applied in the storage to make sure that any harboring Mealybugs which are left on and between the wooden surfaces of the store are killed so as to minimize/ or avoid the next infestation. The measures helped at least to stop the pest from multiplying and spreading to healthy tubers within the store. Sooty mold funguses were developed on seed tubers severely infested by the pest (Figure 1C) and were discarded from the store and buried in the soil.

\section{Importance of the pest in agriculture and management options}

Among the insect pest complex in agricultural ecosystem, Mealybugs (Hemiptera: Pseudococcidae) have ever 
been rated as a major pest, since they play a dual role as pest and vector in field crops. During the last few decades, the Mealybugs, Rhizoecus amorphophalli has emerged as anxious pest infesting on stored tubers of elephant foot yam, taro and tannia (Palaniswami and Pillai,1979; Rajamma et al,. 2002, 2006). This pest is also suspected as a vector of plant diseases (Culik and Gullan, 2005) and has a wide range of variation in morphological characters, biological adaptations and ecological adjustability (Hodgson et al.,2008). Integrated pest management of Mealybug could be the safest and cheapest method of pest control (Ahmad et al., 2003). However, the use of insecticides is inevitable to check the Mealybug outbreaks as compared to predators and parasitoids (McKenzie, 1967; Joshi et al., 2010). Several insecticides belonging to different groups have been documented as effective against potato tuber Mealybug.

\section{Conclusion and recommendation}

Since seed tubers are the basis for potato plant and determines the productivity of the crop, it has to be healthy and free from insect infestation such as Mealybugs. Since Mealybugs are less mobile insects, seed tubers are the most likely means by which the pest can be disseminated to other areas. Hence, there should be an assurance about the health of the seed before sourcing and transporting to other areas. As far as the pest is new in the area, it has to be studied immediately and look for appropriate measures. Verification of appropriate Mealybug management options from recommended packages and awareness creation among different stakeholders about the importance of the pest could be the primary assignment of the respective entomologists. Species identification should also be conducted side by side with the pest management efforts. Moreover, this could be an opportunity for other areas in the country to be aware that the pest is important and make the necessary precautions to avoid unnecessary movement of the pest from one area to another. We also recommend for the responsible government organizations to establish and thoroughly strengthen effective quarantine system to avoid the introduction of exotic insects like Mealybugs to our country and guarantee healthy agricultural production.

\section{References}

Ahmad N, Fatima B, Khan GZ, Nasrullah, Saleem A (2003). Field management of insect pests of cotton through augmentation of parasitoid and predators. Asian J. Plant Sci., 2: 563-565.

Arif MI, Rafiq M, Ghaffar A (2009). Host plants of cotton Mealybug (Phenacoccus solenopsis): a new menace to cotton agro ecosystem of Punjab, Pakistan. Int. J. Agric. Biol., 11: 163-167.

Arsi Zone ARDO (2007). Annual Horticulture Crops Report Arsi Zone (UN Published).

Blumberg D, Swirski E (1977). Mass breeding of two species of Saissetia (Hom: Coccidae) for propagation of their parasitoids.

Buys EM, Nortje GL (1997). Horticultural Crops Post harvest handling, Food industries of South Africa, October issue.

Culik MP, Gullan PJ (2005). A new pest of tomato and other records of Mealybugs (Hemiptera: Pseudococcidae) from Espírito Santo, Brazil. Zootaxa.,964: 1-8.

Elder RJ, Smith D (1995). Mass rearing of Aonidiella orientalis (Newstead) (Hemiptera: Diaspididae) on Butternut Gramma. J. Aust. Entomol. Soc. 34: 253-254.

Food and Agriculture Organization (FAO) (2008). Farmer based seed productionprofitability analysis, Crop Diversification and Marketing Development Project, Asella,Ethiopia.

Gebremedhin WG, Endale G, Berga L (2008). Root and Tuber crops.EIAR.Addis Ababa, Ethiopia.

Hodgson CJ, Abbas G,Arif MI, SaeedS,Karar H (2008). Phenacoccus solenopsis Tinsley (Sternorrhyncha: Coccoidea: Pseudococcidae), a new invasive species attacking cotton in Pakistan and India, with a discussion on seasonal morphological variation. Zootaxa, 1913: 1-33

Johnson T, Giliomee GH (2011). Evaluation of citrus, butternut and sprouting potato as mass rearing substrates for the oleander Mealybug, Paracoccus burnerae (Brain) (Hemiptera: Pseudococcidae). African Journal of Biotechnology 10(42): 8320-8344.

Joshi MD, Butani PG, Patel VN,Jeyakumar P (2010). Cotton Mealybug, Phenacoccus solenopsis. Agric. Rev., 31: 113-119.

McKenzie HL (1967). Mealybugs of California with Taxonomy, Biologyand Control of North American Species (Homoptera: Coccoidea:Pseudococcidae), p: 526. University of California Press, Berkeley.

Miller DR, Miller GL (2002). Redescription of Paracoccus marginatus Williams and Granara de Willink (Hemiptera: Coccoidea: Pseudococcidae) including descriptions of the immature stages and adult male. Proc. Entomol. Soc. Wash. 104: 1-23.

Palaniswami MS, Pillaiks (1979). New records of Mealybug - pseudococcus citriculus G. and Rhizoecus sp.as pests on elephant foot yam under storage. J. Root crops. 5:62.

Rajamma P,Jayaparakas CA, Palaniswami MS (2002). Bio-ecology of storage pests and their natural enemies in aroids and yams. In: Annual Report 2006-2007, Central Tuber Crops Research Institute, Thiruvananthapuram, Kerala. P.54. 
Rajamma P,Jayaparakas CA, Palaniswami MS(2006). Bio-ecology of storage pests and their natural enemies in aroids and yams. In: Annual Report 2006-2007, Central Tuber Crops Research Institute, Thiruvananthapuram, Kerala. 69 pp.

Saini RK, Sharma SSP, Rohilla HR (2009). Mealybug, Phenacoccus solenopsis Tinsley and its survival in cotton ecosystem in Haryana In: Proc. Nation. Symp.onBt-cotton: Opportunities and Prospectus, Central Institute of Cotton Research, p: 150. Nagpur, November 17-19

Walker A, Hoy M, Meyerdirk D (2006). Papaya Mealybug,(Paracoccus marginatus Williams and Granara de Willink (Insecta: Hemiptera: Pseudococcidae)). EENY-302.Featured Creatures.Entomology and Nematology Department.Florida Cooperative Extension Service.Institute of Food and Agricultural Sciences.University of Florida, Gainesville, FL. 